\title{
The Effect of Hypertonic Saline Versus Isotonic Saline Irrigation Following Endoscopic Sinus Surgery- A Comparative Study
}

\author{
Kumar Jitendra ${ }^{1}$, B Vageesh Padiyar ${ }^{1 *}$, Priya Malik ${ }^{1}$ and Arun Kumar ${ }^{2}$ \\ ${ }^{1}$ Senior Resident, Department of Otorhinolaryngology and Head and Neck surgery, Dr Ram Manohar Lohia Hospital, India \\ ${ }^{2}$ Consultant \& Head of Department, Department of Otorhinolaryngology and Head and Neck surgery SGT University, Gurugram, Haryana, India
}

Submission: May 21, 2018; Published: June 05, 2018

*Corresponding author: B Vageesh Padiyar, Senior Resident, Department of Otorhinolaryngology and Head and Neck surgery, Dr Ram Manohar Lohia Hospital, New Delhi- 110001, India, Tel: +919964839201; Email: gpadiyar@hotmail.com

\begin{abstract}
Introduction: Nasal douching solutions have been widely used following endonasal sinus surgery (ESS) . The irrigation solutions reduce synechia formation, enhance mucosal healing and promote the removal of infective debris and crusts.

Objective : To compare the efficacy of hypertonic and isotonic saline solutions used for nasal douching with respect to quality of life following ESS

Materials and Methods: A prospective randomized study was performed. The study included 60 patients who underwent ESS for sinonasal polyposis. Patients were randomly divided into two groups. Group 1 received hypertonic saline (3\%) while the Group 2 received isotonic saline $(0.9 \%)$. Patients were examined on the 7 th, 15 th and 30 th post operative day. Outcomes of hypertonic and isotonic saline irrigation were assessed by saccharine clearance test, endoscopic examination, visual analogue scale and sinonasal outcome test questionnaire.
\end{abstract}

Results: There was no significant difference found in the MCT scores in both the groups. Irrigation with hypertonic saline resulted in better symptom score in SNOT $20(p<0.05)$ and VAS $(p<0.05)$ as compared to isotonic saline. Crusting scores were significantly lower and reappearance of cobblestone mucosa from polypoidal mucosa on endoscopic assessment were better in the group using hypertonic saline irrigation.

Conclusion: Hypertonic saline is the recommended irrigation solution as its use is associated with less crusting, drying and obstruction in the nose for the postoperative period following ESS.

Keywords: Endoscopic sinus surgery; Hypertonic solution; Isotonic solution; Mucociliary clearance

\section{Introduction}

Nasal douching after surgery remains one of the most important post operative management strategies following endoscopic sinus surgery(ESS) [1,2].

Various methods of delivery have been studied in the past, however the high volume and low pressure douching has been considered most effective [3]. Nasal irrigation has shown to clear nasal secretions and infective debris, minimizes crusting, reduces the probability of synechia formation and accelerates mucosal healing [4]. In addition, it has been observed that nasal irrigation appears to improve mucociliary transport function of the nasal mucosa [5].

Various irrigation solutions have been used and their individual advantages and disadvantages have been compared in literature. Isotonic saline irrigation has been used earlier and had been most preferred. 6
Recently hypertonic saline has been the preferred irrigation solution as it has been seen that it reduced edema, improves mucociliary clearance and relieves nasal breathing by affecting osmotic pressure.[4,5,7].

The aim of this study was to compare the effect of hypertonic saline and isotonic saline irrigation for 4 weeks following endoscopic sinus surgery.

\section{Materials and Methods}

A prospective randomized study was performed on 60 patients between the age 18 and 50 . All patients underwent functional endoscopic sinus surgery for nasal polyposis in the Department of Otorhinolaryngology at Dr Ram Manohar Lohia Hospital, New Delhi. The study was performed between October 2015 to September 2017. Informed consent was obtained from all patients and the study was approved by the institutions 
ethics board. Patients included in the study were all new cases of sinonasal polyposis who were resistant to conservative management. Patients who were known cases of mucociliary clearance disorders, smokers and those had undergone previous ESS, chemo-radiotherapy were excluded from our study. The surgeries were performed by different surgeons while examination of patients post surgery was performed by same otolaryngologist. All patients underwent uncinectomy, middle meatal antrostomy, anterior and posterior ethmoidectomy. Frontal and sphenoid sinuses were addressed only in 4 patients. Merocel $\AA$ pack was removed $48 \mathrm{hrs}$ following surgery. In all patients the same post operative medication, oral amoxicillin with clavilunate, was administered for 10 days.

\section{Randomization}

Subjects were randomly divided into 2 groups. Randomization was performed using a table of random numbers for 30 subjects each. Group 1 included numbers 1 to 30 while group 2 included numbers 31 to 60 . Each group had randomly distributed 15 even and 15 odd numbers. Study subjects were then allocated numbers according to the randomization. Those allocated with even numbers received hypertonic saline irritation while those allocated with odd numbers were received isotonic saline irrigation.

\section{Irrigation method}

All subjects were instructed to use irrigation fluids 3 times a day for a period of 4 weeks postoperatively. A total of $60 \mathrm{~mL}$ solution was used for each nasal irrigation, with $30 \mathrm{~mL}$ for each nasal cavity. Irrigation was performed by syringing with the head tilted forward and downward.

\section{Assessing outcome of irrigation}

Measurement of mucociliary clearance: Mucociliary clearance was measured using saccharine clearance test method. Each patient underwent the sacchrarine clearance test postoperatively on the $7^{\text {th }}, 15^{\text {th }}$ and $30^{\text {th }}$ day. A quarter of saccharine tablet was placed on the medial surface of the inferior turbinate, $1 \mathrm{~cm}$ from the anterior end. The time until the subject could taste saccharine was noted. None of the subjects failed to taste saccharine.

Endoscopic assessment: All patients were assessed endoscopically on the $7^{\text {th }}, 15^{\text {th }}$ and $30^{\text {th }}$ postoperative day using a 00 nasal endoscope. During endoscopic assessment crusting and general appearance of nasal mucosa was documented. Crusting was documented as no crusts/few crusts, $<50$ crusts and $>50 \%$ crusts. Endoscopic assessment was documented as either normal, edematous/cobblestoned, polypoidal or gross polypoidal. Assessment of both crusting and endoscopic appearance was done in terms of percentage.

\section{Sinonasal outcome test-20 (SNOT-20) and Visaul analogue scale(VAS)}

Patients were reviewed on the $7^{\text {th }}, 15^{\text {th }}$ and $30^{\text {th }}$ postoperative day with the Sino nasal outcome test and scores were compared on 3 different occasions post surgery. VAS scores were used to assess severity of symptoms, which included nasal blockage/ congestion, headache, facial pain, alteration in sense of small and nasal discharge. A score of 10 was given by patients with no symptoms while a score of 0 was given by patients with worst symptoms.

\section{Statistical analysis}

Apart from the descriptive analysis of the data collected, statistical significance of between group differences was determined using Student's t test, Whitney Rank sum test and Chi-square test. Odds ratios were calculated by cross tabulation with a $95 \%$ confidence interval. Data was tabulated using mean (SD). The magnitude of change in outcome measures of SNOT20 and VAS was determined by using the following calculation for each patient: change=follow up measurement $\left(30^{\text {th }}\right.$ post operative day)- baseline measurement ( $7^{\text {th }}$ day ). To determine if irrigation solution formulation had an effect on the outcome measures, data were analyzed by ANOVA with Bonferroni adjustments. A p value if $<0.05$ was considered to be significant. All statistical analyses were performed using the SPSS (Statistical package programme for social sciences, Chicago,IL,US) (Table 1)

\section{Results}

The study population included 60 patients between 18-55 years of age. Patients were randomly divided into 2 groups with 30 patients in each group. Mean age of group one was 34.9 (2050 ) while in group two was 34.33 (18-55). Group one comprised of 10 females $(33.3 \%)$ and 20 males $(66.6 \%)$ while group two comprised of 12 females (40\%) and 18 males (60\%). There were no significant differences in age distribution or gender distribution ( 0.454 and 0.486 respectively). Each group was examined separately.

Table 1: Endoscopic scores on the amount of crusting with hypertonic saline and isotonic saline.

\begin{tabular}{|c|c|c|c|}
\hline Day of assessment & Endoscopic crusting & Hypertonic saline(\%) & Isotonic saline(\%) \\
\hline \multirow{3}{*}{$7^{\text {th }}$ day } & No crusts & 5 & 6 \\
\cline { 2 - 4 } & $<50 \%$ crusts & 40 & 39 \\
\cline { 2 - 4 } & $>50 \%$ crusts & 55 & 55 \\
\hline \multirow{2}{*}{$15^{\text {th }}$ day } & No crusts & 35 & 41 \\
\cline { 2 - 4 } & $<50 \%$ crusts & 50 & 35 \\
\cline { 2 - 4 } & $>50 \%$ crusts & 15 & 24 \\
\hline
\end{tabular}




\begin{tabular}{|c|c|c|c|}
\hline \multirow{3}{*}{$30^{\text {th }}$ day } & No crusts & 65 & 55 \\
\cline { 2 - 4 } & $<50$ crusts & 25 & 23 \\
\cline { 2 - 4 } & $>50$ crusts & 10 & 22 \\
\hline
\end{tabular}

\section{Mucociliary clearance test (MCT)}

In group 1 and group 2, the MCT values did not significantly change from the $7^{\text {th }}$ to $15^{\text {th }}$ postoperative day $(\mathrm{p}=0.452$ for group 1 and $p=0.343$ for group 2). However the MCT values improved significantly in both groups on the $30^{\text {th }}$ postoperative day $(\mathrm{p}<0.05)$. Each in group variation in MCT was compared with the other group score variations and no significant differences were found. $\left(15^{\text {th }}\right.$ day postoperative- 7 day postoperative, $p=0.453$; 30 th day postoperative- $15^{\text {th }}$ day postoperative, $p=0.112$ ) (Table 2).

Table 2: Endoscopic appearance of nasal mucosa on $7^{\text {th }}, 15^{\text {th }}$ and $30^{\text {th }}$ post operative day in the two groups(hypertonic saline vs. isotonic saline).

\begin{tabular}{|c|c|c|c|}
\hline Day of assessment & $\begin{array}{c}\text { Endoscopic appearance of } \\
\text { mucosa }\end{array}$ & Hypertonic saline(\%) & Isotonic saline (\%) \\
\hline \multirow{4}{*}{$7^{\text {th }}$ day } & Normal & 0 & 0 \\
\hline & Edema/cobblestone & 5 & 5 \\
\hline & Polypoid & 95 & 95 \\
\hline & Gross polypoid & 0 & 0 \\
\hline \multirow{4}{*}{$15^{\text {th }}$ day } & Normal & 0 & 0 \\
\hline & Edema/cobblestone & 56 & 15 \\
\hline & Polypoid & 44 & 85 \\
\hline & Gross polypoid & 0 & 0 \\
\hline \multirow{4}{*}{$30^{\text {th }}$ day } & Normal & 0 & 0 \\
\hline & Edema/cobblestone & 78 & 35 \\
\hline & Polypoid & 28 & 65 \\
\hline & Gross polypoid & 0 & 0 \\
\hline
\end{tabular}

\section{Endoscopic scores}

In the immediate post operative followup ( $7^{\text {th }}$ day) we found that $55 \%$ patients were found to have large amount of crusting ( $>50 \%$ ) within the sinonasal mucosa which improved ( $<50 \%$ crusting) or resolved in all patients. This improvement was consistent among all treatment groups. None of the patients showed gross polypoid disease during the follow up period. However, none of the patients showed a completely normal appearance of the nasal mucosa on the $30^{\text {th }}$ post operative day. The recovery from polypoidal to cobblestone mucosa was better among the patients irrigating with hypertonic saline solution with $56 \%$ cobblestone on $15^{\text {th }}$ day and $78 \%$ on $30^{\text {th }}$ day postoperative day.

\section{Visual analogue scale score (VAS)}

The greatest symptomatic improvement was noted among patients receiving hypertonic saline. The mean improvement in the group receiving hypertonic saline was $12.5 \pm 3.2$ on $15^{\text {th }}$ day and $17.5 \pm 5.4$ on the $30^{\text {th }}$ post operative day. In contrast, the mean improvement in the group receiving hypotonic saline was $8 \pm 2.4$ and $12.4 \pm 2.3$ on the $15^{\text {th }}$ and $30^{\text {th }}$ post operative day respectively.

\section{Sinonasal outcome test-20(SNOT-20)}

The scores in group one showed marked improvement in the SNOT scores with a mean improvement of $23.5 \pm 5.6$ and $31 \pm 3.2$ on $15^{\text {th }}$ and $30^{\text {th }}$ post operative days respectively. While in group two, a modest improvement of $15.5 \pm 4.7$ and $23.3 \pm 4.3$ was noted on the $15^{\text {th }}$ and $30^{\text {th }}$ post operative days respectively.

\section{Discussion}

Nasal irrigation solutions have been widely used for the treatment of sinusitis and in the post operative care of patients who have undergone endonasal procedures. Different kinds of solutions have been used for nasal irrigation such as normal saline, lactated Ringer's solution and various concentrations of hypertonic saline.8,9Nasal douching is considered to improve mucocilary function, decrease mucosal edema, dilute inflammatory mediators and mechanically clear inspissated mucous [10]. Many studies have been done using different topical nasal solutions with varying results [8-12].

This study was done to compare the clinical effectiveness of hypertonic saline and isotonic saline in patients following ESS. Mucociliary clearance is one of the most important host defence mechanisms, playing a critical role in the protection against infections following endonasal surgery. The saccharine clearance test (SCT) is the preferred method in assessing mucociliary clearance since it is inexpensive, can be easily applied and is reliable [8]. The use of hypertonic solutions for nasal irrigation has increased in the recent past since it is reported to have a better outcome in terms of mucociliary clearance by mitigating edema, inflammation and decreasing mucus viscosity due it the 
alkaline nature $[4,5]$. In addition, it has been reported to improve mucociliary clearance in patients with cystic fibrosis and asthma $[13,14]$.

The exact mechanism related to improvement in mucociliary clearance is still not clear. Some studies suggest hypertonic solutions to increase $\mathrm{Ca}^{+2}$ release from intracellular stores stimulating the ciliary beat frequency possibly by regulating the use or availability of adenosine triphosphate by the ciliary axoneme [20].

Inspite of its advantages, hypertonic saline is reported to cause burning sensation due to the stimulation of nociceptive nerves and subsequent substance P release. 15,18,19 Hypertonic saline is also known to cause histamine release which further leads to nasal hyper reactivity and hypersecretion causing decrease in nasal airway volume $[15,17]$.

Keojampa et al found no difference between the effect of hypertonic and isotonic saline in terms of improvement in breathing while Hauptman et al found that buffered isotonic saline significantly relieved nasal obstruction as compared to hypertonic saline $[5,16]$. All our patients used high volume low pressure nasal irrigation technique with good outcomes. Similar observations were made by Salib et al who reported high volume low pressure saline irrigations to be more effective than low volume high pressure saline irrigations following ESS in the early post operative period; however, there were no differences noted in ease of use [21]. The limitations of this study include the study not being double blinded, lack of rhinomanometry and lack of long term follow-up of post operative patients.

\section{Conclusion}

Nasal irrigation post ESS is effective in symptom resolution and normalization of mucosa appearance. Hypertonic saline irrigation was significantly more effective as compared to isotonic saline.

\section{References}

1. Fokkens WJ, Lund VJ, Mullol J (2012) EPOS 2012: European position paper on rhinosinusitis and nasal polyps 2012. A summary of Otorhinolaryngologists Rhinology 50(1): 1-12.

2. Fernandes SV (1999) Postoperative care in functional endoscopic sinus surgery? Laryngoscope 109(6): 945-948.

3. Harvey RJ, Goddard JC, Wise SK, Schlosser RJ (2008) Effects of endoscopic sinus surgery and delivery device on cadaver sinus irrigation. Otolaryngol Head Neck Surg 139(1): 137-142.

4. Talbot AR, Herr TM, Parsons D (1997) Mucociliary clearance and buffered hypertonic saline. Laryngoscope 107(4): 500-503.
5. Keojampa KB, Nguyen MH, Ryan MW (2004) Effects of buffered saline solution on nasal mucociliary clearance and nasal airway patency. Otolaryngol Head Neck Surg 131(5): 679-682.

6. Unal M, Seymen HO (2002) Effect of Ringer-Lactate and isotonic saline solutions on mucociliary clearance of tracheal epithelium: an experimental study in rats. J Laryngol Otol 116(7): 536-538.

7. Shone GR, Yardley MP, Knight LC (1990) Mucociliary function in the early weeks after nasal surgery. Rhinology 28(4): 265-268.

8. Boek WM, Keles N, Graamans K (1999) Physiologic and hypertonic saline solutions impair ciliar activity in vitro. Laryngo-scope 109(3): 396-399.

9. Wormald PJ, Cain T, Oates L (2004) A comparative study of three methods of nasal irrigation. Laryngoscope 114(12): 2224-2227.

10. Tomooka LT, Murphy C, and Davidson TM (2000) Clinical study and literature review of nasal irrigation. Laryngoscope 110(7): 1189-1193.

11. Homer JJ, Dowley AC, Condon L, El-Jassar P, Sood S (2000) The effect of hypertonicity on nasal mucociliary clearance. Clin Otolaryngol Allied Sci 25(6): 558-560.

12. Shone GR, Yardley MP, Knight LC (1990) Mucociliary function in the early weeks after nasal surgery. Rhinology 28(4): 265-268.

13. Robinson M, Regnis JA, Bailey DL, King M, Bautovich GJ, et al. (1996) Effect of hypertonic saline, amiloride, and cough on mucociliary clearance in patients with cystic fibrosis. Am J Respir Crit Care Med 153(5): 1503-1509.

14. Daviskas E, Anderson SD, Gonda I (1996) Inhalation of hypertonic saline aerosol enhances mucociliary clearance in asth- matic and healthy subjects. Eur Respir J 9(4): 725-732.

15. Lansley AB, Sanderson MJ, Dirksen EP (1992) Control of the beat cycle of respiratory tract by $\mathrm{Ca}^{+2}$ and cAMP. Am J Physiol 263: L232-242.

16. Freidman M, Vidyasagar R, Joseph N (2006) A randomized, prospective, double-blind study on the eciacy of Dead Sea salt nasal irrigations. Laryngoscope 116(6): 878-882.

17. Baraniuk JN, Ali M, Yuta A, (1999) Hypertonic saline nasal provocation stimulates nociceptive nerves, substance $\mathrm{P}$ release, and glandular mucous exocytosis in normal humans. Am J Respir Crit Care Med 160(2): 655-662.

18. Ganong W (2012) Chapter 7: Neurotransmitters \& Neuromodulators. In Review of Medical Physiology, (24 edn); Barrett KE, Boitano S, Barman SM and Brooks HL (Eds). McGraw Hill, Lange Medical Publisher, New York, USA, pp. 135-154.

19. Baraniuk JN, Ali M, Naranch K (2002) Hypertonic saline nasal provocation and acoustic rhinometry. Clin Exp Allergy 32(4): 543-550.

20. Hauptman G, Ryan MW (2007) The effect of saline solutions on nasal patency and mucociliary clearance in rhinosinusitis patients. Otolaryngol Head Neck Surg 137(5): 815-821.

21. Salib RJ, Talpallikar S, Uppal S, Nair SB (2013) A prospective randomised single-blinded clinical trial comparing the efficacy and tolerability of the nasal douching products Sterimar ${ }^{\mathrm{TM}}$ and Sinus Rins $^{\mathrm{TM}}$ following functional endoscopic sinus surgery. Clin Otolaryngol 38(4): 297-305. 

(C) This work is licensed under Creative

DOI: $10.19080 / G J O .2018 .15 .555925$
Your next submission with Juniper Publishers will reach you the below assets

- Quality Editorial service

- Swift Peer Review

- Reprints availability

- E-prints Service

- Manuscript Podcast for convenient understanding

- Global attainment for your research

- Manuscript accessibility in different formats

( Pdf, E-pub, Full Text, Audio)

- Unceasing customer service

Track the below URL for one-step submission https://juniperpublishers.com/online-submission.php 